\title{
Impacto da Central Termoeléctrica do Pego sobre o Rio Tejo
}

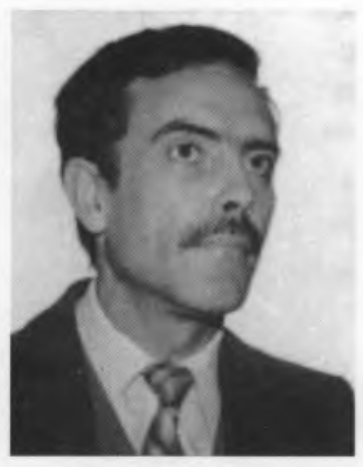

João A. Lopes Rosa

É Licenciado em Engenharia Química (IST).

Tem experiência profissional em Engenharia do Ambiente, desenvolvida a partir de 1978, na qualidade de técnico superior do Gabinete da Área de Sines.

Ao serviço da Electricidade de Portugal, EP (EDP) desde 1983, continuou a exercer actividade no mesmo domínio, no Departamento de Sítios e Ambiente da Direcção do Equipamento Térmico, onde tem sido responsável pelo desenvolvimento de numerosos estudos de ambiente associados ao projecto de Centrais Térmicas.

\section{Introdução}

Entre os novos centros produtores da Electricidade de Portugal, E.P. actualmente em fase de construção, destaca-se a Central Térmica do Pego (Abrantes), com uma potência total idêntica à instalada na C.T. Sines (4 grupos de $300 \mathrm{MWe}$ cada).

Pela primeira vez em centrais térmicas nacionais, serão usadas torres para refrigeração da água que circula pelos condensadores. Neste tipo de circuitos, o caudal de alimentação de água reduz-se ao indispensável para compensar as perdas por evaporação e pela purga, operação que é necessária para controlar o aumento do teor em sólidos dissolvidos.

O Rio Tejo, sendo o meio fornecedor de água e simultaneamente receptor dos efluentes da Central, foi alvo de um estudo de impacto ambiental de que se apresenta em seguida uma breve síntese.

O desenvolvimento do estudo baseou-se esquematicamente nas seguintes fases:

- Caracterização do estado de referência do ecossistema em causa;

- Identificação, análise e optimização dos factores do projecto com potencial incidência nesse ecossistema;

- Avaliação do impacto ambiental expectável.

\section{Estado de Referência}

Dada a escassez de dados pré-existentes aplicáveis ao troço do rio com interesse para este estudo, tornou-se necessário desenvolver uma campanha de amostragem e análise, de cujos resultados se apresenta no Quadro 1 um extractosíntese que inclui referências comparativas com critérios de qualidade estabelecidos em directivas CEE susceptíveis de aplicabilidade.

É notória a existência de gamas de variação muito acentuadas para alguns parâmetros, não só em termos anuais mas também em períodos mais curtos. Embora não necessariamente coincidente no tempo, este carácter de irregularidade manifesta-se também relativamente aos caudais que, durante o período de 1973 a 1986, variaram entre as médias anuais de $53,5 \mathrm{~m}^{3} / \mathrm{s}(1980 / 81)$ e $694 \mathrm{~m}^{3} / \mathrm{s}$ (1978/79) (Estação hidrométrica do Tramagal).

De forma genérica, este troço do rio pode considerar-se como pouco poluído mas sujeito a um grau de eutrofização significativo, traduzido pelos valores elevados dos nutrientes (em particular o fósforo), bem como pelos resultados obtidos para diversos factores bióticos.

Apesar das características lóticas da zona fluvial do Pego, a comunidade biótica local apresenta uma estrutura influenciada pela proximidade das barragens a montante e também pelo respectivo regime de descarga que, sendo irregular, determina variações consideráveis e frequentes quer na velocidade da corrente quer nos níveis da água.

Tomando por referência apenas o nível trófico mais elevado,

"EDP - Direcção do Equipamento Térmico/Departamento de Sítios e Ambiente. 
QUADRO 1

Qualidade da água do Rio Tejo-Resultados

PEGO / Set. 85 - Dez. 87 - Laboratório de Sacavém (EDP) - Instituto de Zoologia (FCUP)

\begin{tabular}{|c|c|c|c|c|c|c|c|}
\hline & MÉDIA & MÁX. & MÍN. & No. det. & LIM. CEE & a ) & $\begin{array}{l}\text { t/Obs. } \\
\text { (b) }\end{array}$ \\
\hline Temperatura $\left({ }^{\circ} \mathrm{C}\right)$ & 16.3 & 23.5 & 10.2 & 36 & $25 / 28$ & $\mathrm{~A} / \mathrm{P}$ & $(\mathrm{O})$ \\
\hline $\mathrm{pH}$ & 7.4 & 8.7 & 6.4 & 36 & 6-9 & $\mathrm{P}$ & $(\mathrm{O})$ \\
\hline Condut. eléctrica $(\mu \mathrm{S} / \mathrm{cm})$ & 406 & 500 & 210 & 36 & 1000 & A (G) & \\
\hline Oxigénio diss. (mg/l) & 8.4 & 11.3 & 5.6 & 36 & $50 \%>=7$ & $\mathrm{P}$ & \\
\hline Satur. Oxigénio diss. (\%) & 85 & 110 & 60 & 36 & $80-120$ & $B \cdot(G)$ & \\
\hline Matérias em suspensão $(\mathrm{mg} / \mathrm{l})$ & 8.2 & 32.8 & 3.2 & 28 & 25 & $P(G)$ & $(\mathrm{O})$ \\
\hline Alcalin. (met.) (mg/l $\left.\mathrm{CaCO}_{3}\right)$ & 60.2 & 72.5 & 40.0 & 36 & & & \\
\hline Dureza total $\left.(\mathrm{mg} / \mathrm{l} \mathrm{CaCO})_{3}\right)$ & 130.9 & 162.0 & 77.2 & 28 & & & \\
\hline Amónia $\left(\mathrm{mg} / 1 \mathrm{NH}_{4}\right)$ & 0.21 & 0.87 & $<0.05$ & 36 & 1.00 & $\mathrm{P}$ & $(\mathrm{O})$ \\
\hline Amoníaco não ionizado (mg/l) & 0.004 & 0.033 & 0.000 & 36 & 0.025 & $\mathrm{P}$ & \\
\hline Cloretos $(\mathrm{mg} / \mathrm{l})$ & 32.4 & 42.6 & 17.5 & 28 & 200 & $A(G)$ & \\
\hline Nitritos (mg/l) & 0.036 & 0.144 & $<0.003$ & 36 & 0.03 & $P(G)$ & \\
\hline Nitratos (mg/l) & 3.64 & 5.85 & 1.63 & 36 & 50 & A & \\
\hline Sulfatos $(\mathrm{mg} / \mathrm{l})$ & 84.8 & 113.5 & 37.7 & 28 & 250 & A & $(\mathrm{O})$ \\
\hline Fosfatos $(\mathrm{mg} / \mathrm{l})$ & 0.70 & 1.30 & 0.43 & 36 & 0.47 & A (G) & \\
\hline Fósforo total $\left(\mathrm{mg} / \mathrm{l} \mathrm{PO}_{4}\right)$ & 0.78 & 1.55 & 0.43 & 36 & 0.4 & $P(G)$ & \\
\hline Oxidabil. $\mathrm{KMnO}_{4}\left(\mathrm{mg} / \mathrm{l} \mathrm{O}_{2}\right)$ & 5.4 & 7.3 & 3.8 & 36 & & & \\
\hline $\mathrm{CBO}_{5}\left(\mathrm{mg} / \mathrm{l} \mathrm{O}_{2}\right)$ & 1.6 & 4.7 & 0.4 & 33 & 5 & A (G) & \\
\hline Ferro total $(\mathrm{mg} / \mathrm{l})$ & 0.14 & 0.42 & 0.04 & 28 & & & \\
\hline Ferro dissolvido $(\mathrm{mg} / \mathrm{l})$ & & & & & 2 & A & \\
\hline Cobre (mg/l) & 0.007 & 0.018 & $<0.005$ & 28 & 0.05 & $A(G)$ & \\
\hline Zinco $(\mathrm{mg} / \mathrm{l})$ & 0.015 & 0.052 & $<0.020$ & 28 & 1.0 & $\mathrm{P}$ & \\
\hline Mercúrio $(\mu \mathrm{g} / \mathrm{l})$ & 0.02 & 0.05 & $<0.01$ & 5 & 0.001 & A & \\
\hline Extracto éter pet. (mg/l) & 1.3 & 4.8 & n.d. & 5 & 0.2 & A & \\
\hline Fenóis $(\mathrm{mg} / \mathrm{l})$ & 0.005 & 0.013 & $<0.005$ & 5 & 0.005 & A & \\
\hline Coliformes totais $/ 100 \mathrm{ml}$ & 625 & 2400 & 0 & 23 & 10000 & B & \\
\hline Escherichia coli /100 ml & 248 & 1100 & 4 & 23 & 2000 & B & \\
\hline Estreptococos fecais $/ 100 \mathrm{ml}$ & 71 & 460 & 0 & 23 & 100 & $\mathrm{~B}(\mathrm{G})$ & \\
\hline Clorofila a $\left(\mathrm{mg} / \mathrm{m}^{3}\right)$ & 9.17 & 37.64 & 0.89 & 19 & & & \\
\hline
\end{tabular}

\section{NOTAS}

(a) A - Directiva 75/440/CEE (nível de tratamento A2); B - Directiva 76/160/CEE; P - Directiva 78/658/CEE

(b) (G) - Valor guia; (O) - Previstas derrogações para condições climáticas ou geográficas excepcionais.

verifica-se que a população piscícola se apresenta bastante diversificada. Os ciprinídeos, cuja resistência a condições adversas do meio (por exemplo, às variações térmicas) é bem conhecida, constituem o grupo mais representado. Importa, todavia, mencionar também a importância das populações migradoras, designadamente a lampreia, a enguia, a taínha, a savelha e o sável, este último porém em grande regressão.

\section{Factores de Impacto}

Caracterizado o ecossistema fluvial e ponderados os dados técnicos do projecto, identificaram-se os seguintes factores de impacto principais:

- Evaporação de água nas torres de refrigeração;

- Descarga de águas de purga do circuito de refrigeração; 
- Descarga dos efluentes da respectiva estação de tratamento;

- Cloragem da água;

- Adição de ácido à água de refrigeração («Vacinação»);

- Captação da água do Rio Tejo.

A concepção destes sistemas foi optimizada com vista à mitigação dos respectivos impactos, conduzindo por fim à obtenção dos resultados que em seguida se apresentam em síntese.

\section{Avaliação de Impacto}

As perdas de água por evaporação têm um valor desprezável $\left(0,6 \mathrm{~m}^{3} / \mathrm{s}\right)$ face ao caudal médio plurianual do rio $\left(256 \mathrm{~m}^{3} / \mathrm{s}\right)$, mas adquirem certa expressão em situações de estiagem, representando $7 \%$ em relação ao caudal mínimo indicado na autorização de estabelecimento da Central $\left(8 \mathrm{~m}^{3} / \mathrm{s}\right)$.

Tendo em atenção que o caudal da purga é da ordem de grandeza de $0,5 \mathrm{~m}^{3} / \mathrm{s}$, a realimentação de água necessária perfaz cerca de $1,1 \mathrm{~m}^{3} / \mathrm{s}$.

No que se refere ao calor residual descarregado, verifica-se que a temperatura da purga pode atingir valores relativamente elevados, consoante as condições climatéricas, nomeadamente a temperatura do ar e a humidade relativa (Figura 1).

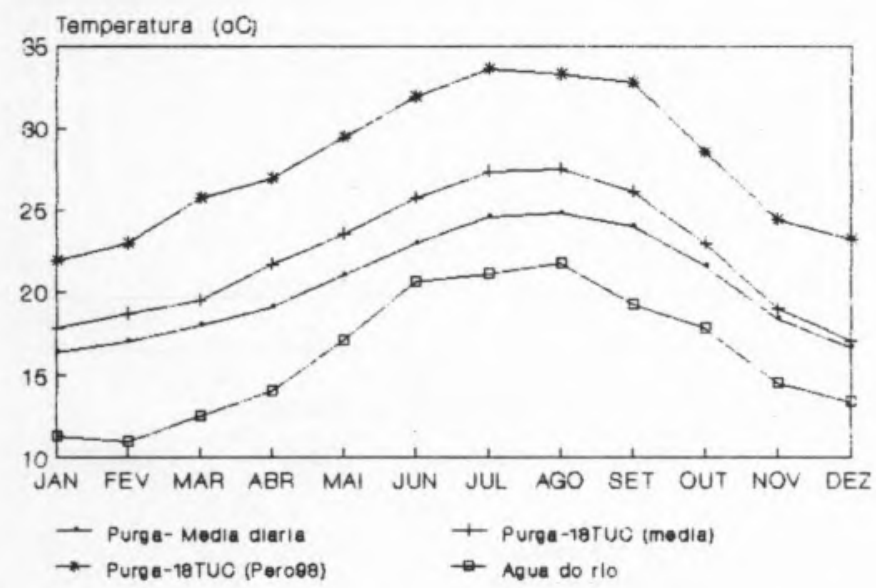

FIGURA 1

Temperatura da purga do Circuito de Refrigeraçâo

O impacto térmico no rio foi estudado com o auxílio de um modelo matemático de simulação (adaptado do modelo QUAL II da Agência de Protecção do Ambiente dos E.U.A.). Conforme se ilustra nas Figuras 2 e 3, e apesar dos valores elevados que a temperatura da purga pode atingir, o aumento de temperatura só adquire expressão sensível para caudais do rio muito reduzidos, mantendo-se mesmo assim em valores da ordem de grandeza de $1{ }^{\circ} \mathrm{C}$ quando o caudal do rio desce até $8 \mathrm{~m}^{3} / \mathrm{s}$.

Tendo em conta o contacto íntimo ar-água verificado ao nível das torres de refrigeração, a diminuição expectável do oxigénio dissolvido a jusante da descarga é muito pequena $(<0,2 \mathrm{mg} / \mathrm{l})$.

Os diversos tipos de efluentes de carácter industrial são sujeitos a tratamento em instalações adequadas, sendo posteriormente adicionados à purga das torres de refrigeração.

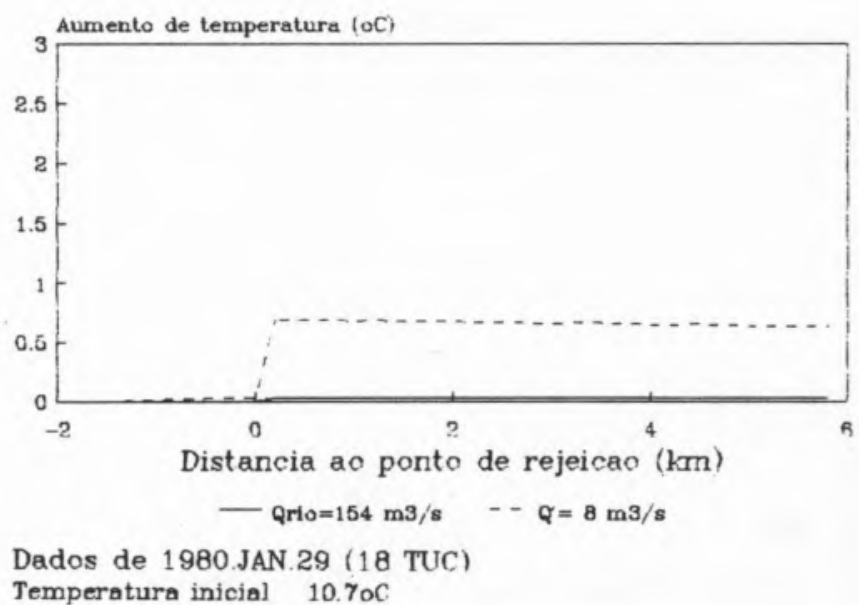

FIGURA 2

Aumento da temperatura no Rio. Situaçâo típica de Inverno

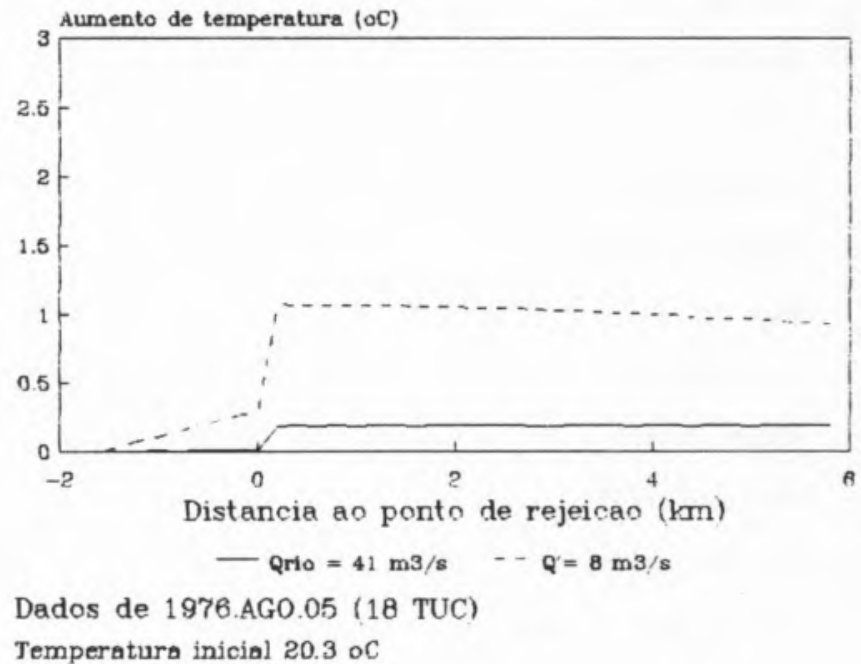

FIGURA 3

Aumento da temperatura no Rio. Situação típica de Verão

Dadas as características médias do efluente tratado (Quadro 2), apenas em situações muito excepcionais, mormente em resultado de operações de limpezas químicas das caldeiras, se torna previsível um aumento da carga poluente gerada, mais sensível no que respeita ao teor em azoto amoniacal (Figura 4).

Por ser possível tirar partido do valor elevado da taxa de degradação química do cloro, mantendo a purga fechada quando se efectuam as operações de cloragem do circuito de refrigeração, a descarga daquele oxidante residual traduzirse-á por valores muito inferiores aos níveis regulamentares internacionais.

A prevenção do aparecimento de incrustações salinas no circuito de refrigeração poderá exigir, em ocasiões de muito elevada produção fotossintética no rio, a injecção de um ácido (sulfúrico ou clorídrico) cujo único efeito será o aumento de concentração do ião correspondente (sufato ou cloreto) na purga.

Por último, refira-se que a mortalidade dos pequenos organismos, nomeadamente os planctónicos, arrastados para o 
QUADRO 2

Composição típica dos efluentes da Estaçẫo de Tratamento de Águas Residuais (a)

\begin{tabular}{|c|c|c|}
\hline & $\begin{array}{l}\text { MÉDI } \\
\text { (b) }\end{array}$ & \\
\hline $\mathrm{pH}$ & 7.6 & \\
\hline Condut. eléctrica $(\mu \mathrm{S} / \mathrm{cm})$ & 2064 & \\
\hline Sólidos suspensos $(\mathrm{mg} / \mathrm{l})$ & 23.3 & \\
\hline Azoto amoniacal (mg/l NH4+) & 1.55 & (c) \\
\hline Nitritos (mg/l) & 0.104 & \\
\hline Nitratos $(\mathrm{mg} / \mathrm{l})$ & 1.81 & (d) \\
\hline Fosfatos $(\mathrm{mg} / \mathrm{l})$ & 0.10 & \\
\hline Fósforo total (mg/l PO4) & 0.20 & \\
\hline Oxidabil. KMn 04 (mg/l 02) & 4.9 & \\
\hline CBO5 (mg/l 02) & 4.0 & \\
\hline Ferro $(\mathrm{mg} / \mathrm{l})$ & 0.05 & \\
\hline Cobre $(\mathrm{mg} / \mathrm{l})$ & 0.027 & \\
\hline Zinco (mg/l) & 0.030 & \\
\hline Mercúrio $(\mu \mathrm{g} / \mathrm{l})$ & 0.43 & \\
\hline Ext. éter pet. (mg/l) & 0.00 & \\
\hline Deterg. aniónicos (mg/l) & 0.09 & \\
\hline
\end{tabular}

(a) Dados obtidos com base numa campanha de análises dos efluentes da E.T.A.R. da C.T. Sines.

(b) Antes da diluição na purga do C.A.R.

(c) No caso de existirem efluentes de limpezas químicas, considerar 3.8 $\mathrm{mg} /$.

(d) No caso de existirem efluentes de limpezas químicas, considerar 5.0 $\mathrm{mg} /$.

interior do circuito de refrigeração através do sistema de captação da água, não terá qualquer efeito sensível sobre o ecossistema fluvial.

\section{Conclusões}

De acordo com os resultados apresentados, terá uma expressão muito reduzida o impacto da Central Térmica do Pego sobre o meio hídrico receptor dos seus efluentes - o Rio Tejo. Esta conclusão é consequência, por um lado das características do ecossistema fluvial, e por outro lado do facto de

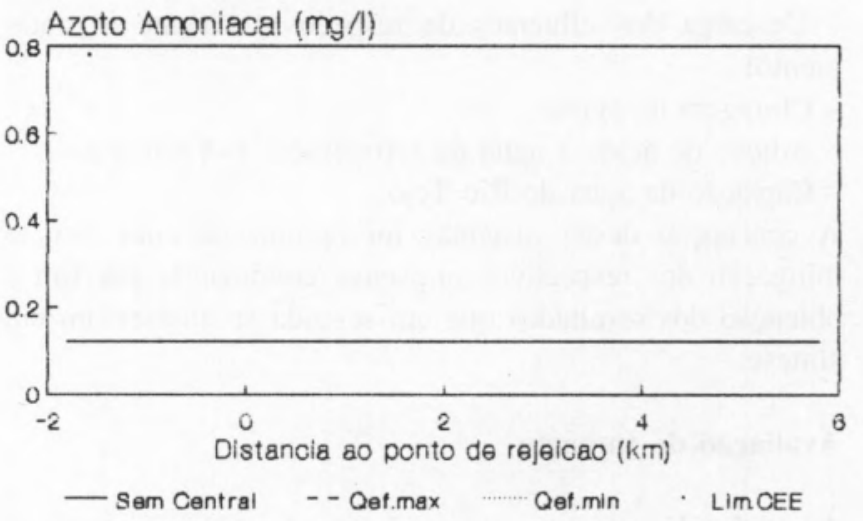

Dados meteor de 1974 MAl 14

Caudal do rio $\mathrm{Qr}=271 \mathrm{~m} 3 / \mathrm{s}$

Dados fis.quim de 1986.MAl. 13

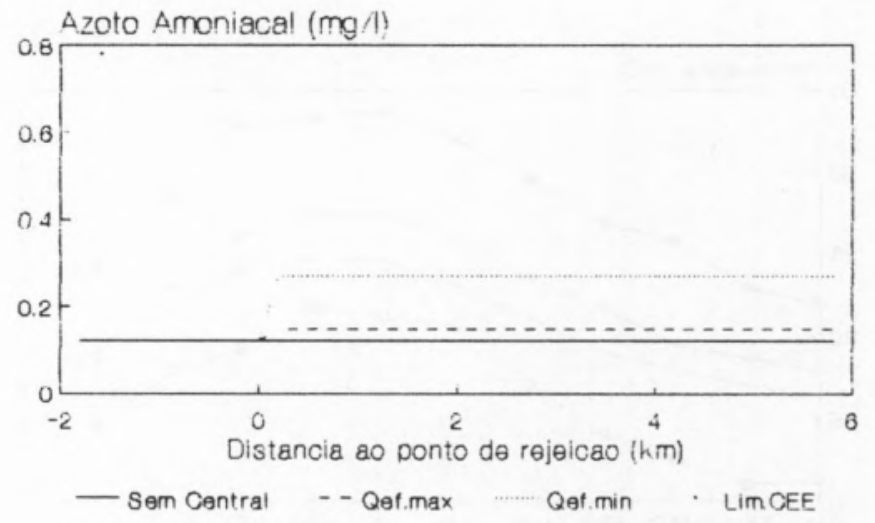

Dados meteor de 1974.MAI.14

Caudal assumido $Q^{\prime}=8 \mathrm{~m} 3 / \mathrm{s}$

Dados fis.quim de 1986.MAl.13

FIGURA 4

Aumento do teor em azoto amoniacal no Rio. Situação desfavorável

terem sido adoptados no projecto sistemas e equipamentos em cuja concepção se fizeram intervir desde o início critérios de protecção ambiental, designadamente ao nível do Circuito de Refrigeração Principal e da Estação de Tratamento de Águas Residuais.

Para além destas medidas, e também no sentido de minimizar o referido impacto, salienta-se que, dada a existência de uma albufeira situada a montante da região do Pego (Barragem de Pracana, no Rio Ocreza), cuja capacidade de armazenagem é susceptível de ser utilizada para compensar caudais muito baixos do Tejo, será possível desta maneira prevenir os efeitos devidos a situações de estiagem intensa. 


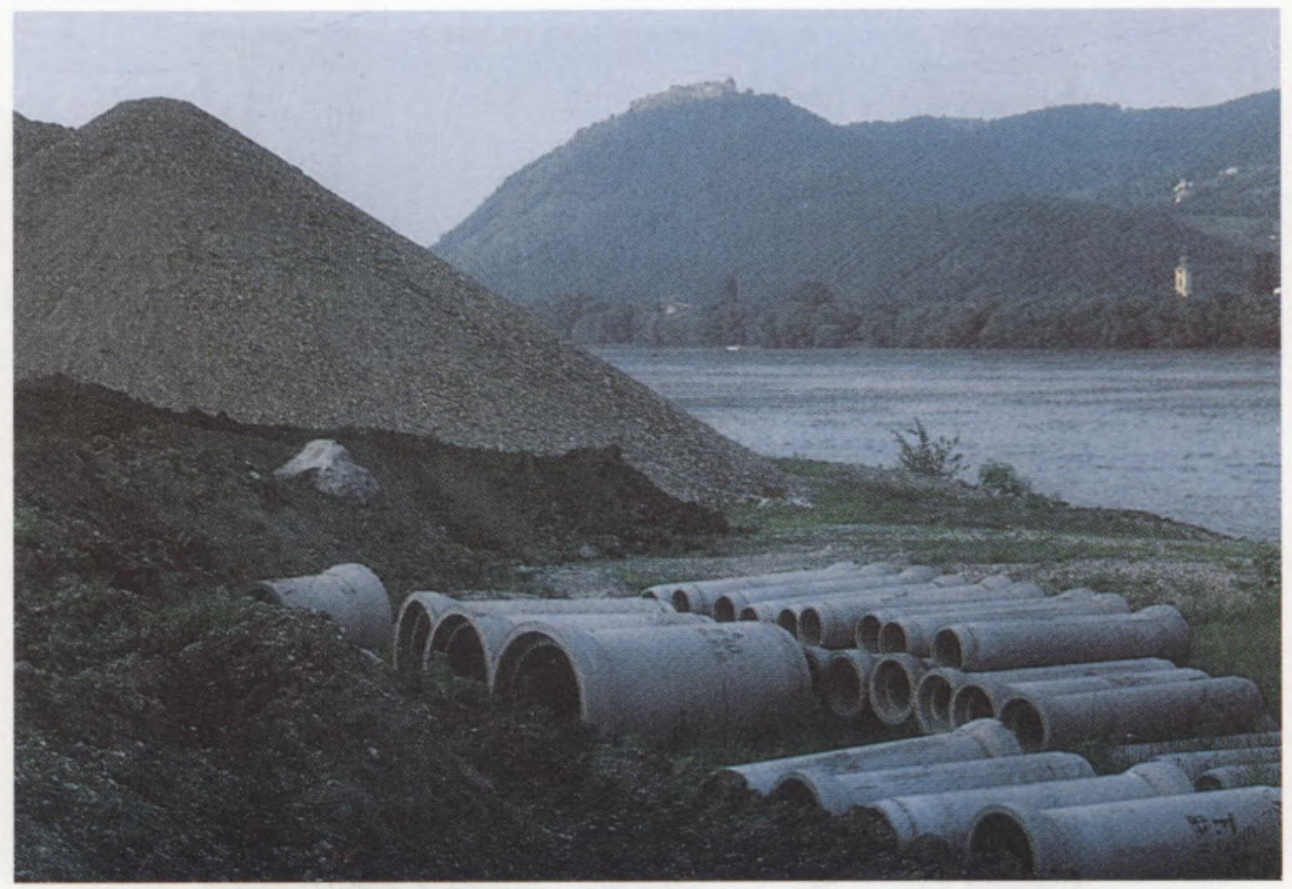

Seis Rios

Embora os responsáveis garantam que a há "casos bem piores" nos outros países europeus, a verdade é que reconhecem "situações críticas" nos rios Leça, Ave, Almonda, Alviela, Trancão e Nabão.

Dado este alerta, vale a pena passar em revista as principais causas de poluição das águas residuais "superficiais e subterrâneas". Além das carências de tratamento de esgotos domésticos, os efluentes industriais são os que "mais gravemente" deterioram os meios hídricos. Os "grandes poluidores" são as indústrias da celulose, têxtil e químicas; entre os "poluidores localizados" contam-se os curtumes, as destilarias de vinho, os lagares de azeite, as instalações pecuárias, os matadouros, as extracções de minerais não metálicos e algumas metalomecânicas. 


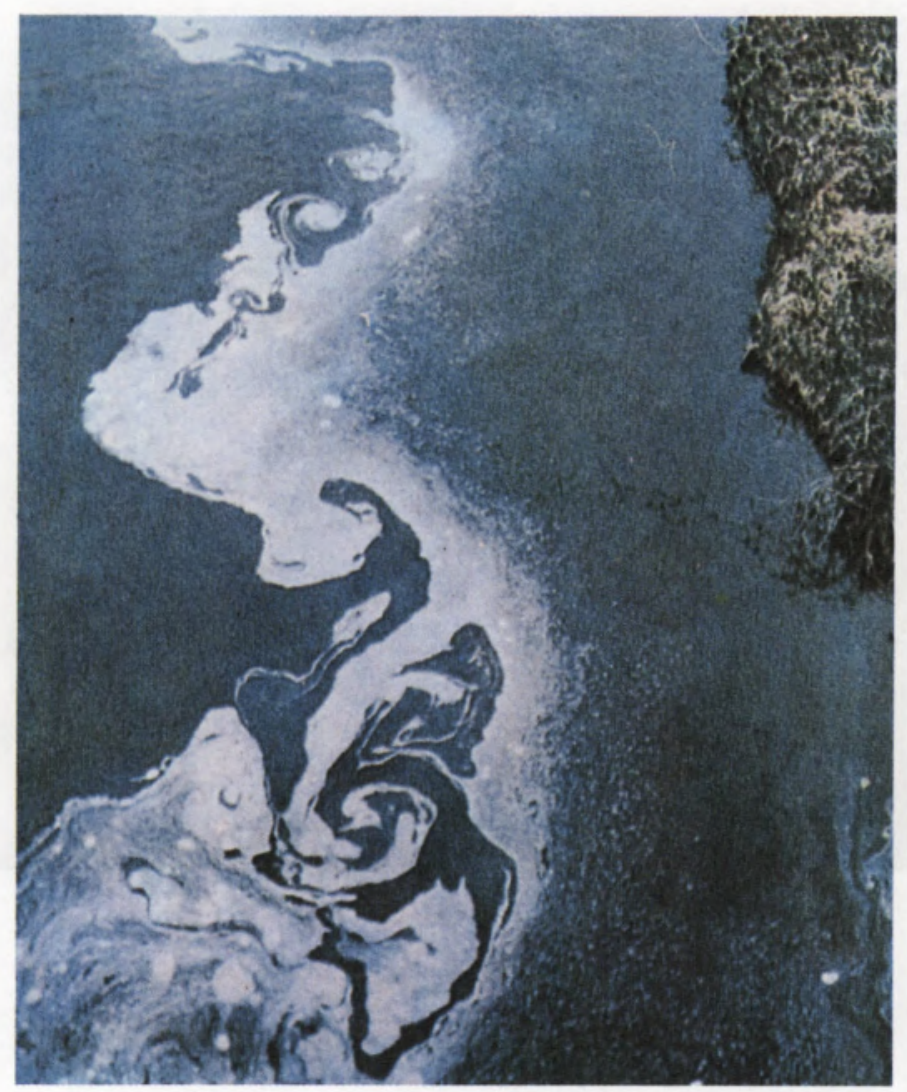

\section{A "Tensão" da Água}

Os detergentes de acção superficial dão origem a um tipo especial de poluição orgânica. Eles são usados muitas vezes como adjuvantes dos pós para lavagem. O seu efeito assenta numa diminuição da tensão da água. Os animais aquáticos de tegumento mole (moluscos, por exemplo) são mortos por estes produtos. As aves aquáticas cujas plumas oleosas são refractárias à molhadura, embebem-se de água e afundam-se. À superfície da água forma-se uma película que impede a absorção da água e provoca o aparecimento de sintomas de penúria de oxigénio. Nos casos de poluição grave, assiste-se à formação de massas de espuma. 